\title{
ANALISIS KONDISI FISIK ATLET WUHSU KABUPATEN LIMAPULUH KOTA
}

\author{
Fauziati Tri Noviani ${ }^{1}$, Hanif Badri ${ }^{2}$ \\ Universitas Negeri Padang
}

\begin{abstract}
The problem in this study is that there is no training center on the physical condition of athletes and coaches have no data about the abilities of the athletes they develop. During training the trainer only focuses on training the components of the physical condition of endurance of the heart and lungs (cardiorespiratory) only. Whereas to support an athlete's achievement improvement, a coach should also know the quality of the components of other physical conditions such as strength, agility, explosive power, speed, and strength.

This type of research is quantitative descriptive. The population in this study were Wuhsu athletes in Limapuluh Kota Regency, which numbered 15 male athletes. The sampling technique uses purposive sampling. Thus the sample in this study amounted to 15 male athletes. To obtain data tests and measurements were made on the abilities of the athlete's physical condition. Data were analyzed using descriptive analysis with percentages.

The results of the study of physical conditions with tests and measurements showed that the physical condition of the largest percentage was as follows: (1) Muscle Power of Wushu athletes was $57.14 \%$ in the moderate category, (2) Stomach Strength of Wushu athletes was $71.43 \%$ in good category, ( 3 ) Muscle Strength of $78.57 \%$ Wushu athletes in the less category, (4) The speed of $50 \%$ Wushu athletes in the medium category, (5) The agility of $35.71 \%$ Wushu athletes in the medium category (6) Endurance Wushu athletes $64.29 \%$ in the moderate category.
\end{abstract}

\section{Keywords: Physical Condition, Wushu Athletes,}

\section{PENDAHULUAN}

Prestasi olahraga yang tinggi tidak akan terlepas dari proses yang panjang dan tidak bisa dicapai secara tiba-tiba (instans) melainkan ada banyak hal yang berpengaruh. Untuk itu diperlukan perhatian khusus, salah satunya dengan pembinaan atlet-atlet berbakat yang diterapkan di daerah-daerah. Dengan penerapan sistem pembinaan tersebut, nantinya akan membentuk proses latihan berkualitas yang diharapkan bisa mencetak bibit-bibit atlet handal yang mampu untuk meraih prestasi.

Hakikat olahraga merupakan kegiatan fisik yang mengandung sifat permainan dan berisi perjuangan melawan diri sendiri atau dengan orang lain atau konfrontasi dengan unsur-unsur alam. Olahraga meliputi gaya 
pertandingan, maka kegiatan itu harus dilaksanakan dengan semangat atau jiwa sportif. Pada olahraga kelompok mendorong manusia saling bertanding

dalam suasana kegembiraan dan kejujuran. Olahraga memberi kemungkinan pada tercapainya rasa saling mengerti dan menimbulkan solidaritas serta tidak mementingkan diri sendiri.

Olahraga juga dapat membuat tubuh seseorang menjadi sehat jasmani dan rohani yang akhirnya akan membentuk manusia yang berkualitas. Mengingat pentingnya peranan olahraga dalam kehidupan manusia, juga dalam usaha ikut serta memajukan manusia Indonesia berkualitas, maka pemerintah Indonesia mengadakan pembinaan dan pengembangan di bidang olahraga, seperti mengadakan pertandingan-pertandingan olahraga yang biasanya diikuti oleh para olahragawan. Untuk memperoleh tingkat kesehatan dan kebugaran yang baik, maka dapat diperoleh dengan olahraga yang dimulai sejak dini melalui pendidikan formal maupun non formal.

Olahraga dapat dijadikan ajang kompetisi untuk berpacu dalam pencapaian sebuah prestasi. Untuk itu dalam pencapaian prestasi yang baik maka dibutuhkan pembinaan yang terarah dan terorganisir, serta terprogram dengan baik. Berkaitan dengan sistem pembinaan dan pengembangan olahraga pemerintah Indonesia membentuk suatu wadah organisasi nasional yaitu KONI yang menaungi berbagai cabang olahraga antara lain olahraga beladiri Wushu.

Wushu merupakan olahraga beladiri yang berasal dari Negara Cina dan mulai berkembang di Indonesia. Yang terdiri dari beberapa cabang yaitu Wushu Taulo (seni jurus) dan Wushu Sanda (tarung). Wushu Sanda (tarung) adalah sistem beladiri full contact atau pertarungan bebas (combat sport), yang sering disejajarkan dengan cabang olahraga tarung lain seperti Muaythai, Taekwondo, dan Kickboxing. Sanda/Sanshou meliputi teknik bertarung satu lawan satu dimana di dalamnya terdapat elemen-elemen yang sifatnya dapat mencederai lawan sehingga pada tingkat kompetisi harus mengikuti peraturan-peraturan yang telah ditetapkan. Saat ini di Indonesia, cabang olahraga beladiri Wushu baik Taulo maupun Sanda/Sanshou merupakan salah satu cabang olahraga beladiri yang dipertandingkan di multy event mulai dari tingkat daerah maupun tingkat nasional, seperti Kejurkab, Kejurprov, Kejurnas, Popnas dan bahkan 
PON. Pada tahap kompetisi, kategori Sanda/Sanshou dibagi menjadi 3 ronde, batas waktu setiap ronde adalah 2 menit dengan waktu istirahat 1 menit disetiap ronde.

Seiring berkembangnya tingkat kompetisi dan daya saing atlet untuk mencapai prestasi tertinggi maka diselenggarakan berbagai macam kompetisi pada berbagai tingkatan yang tujuannya agar dapat mengikuti jenjang kejuaraan pada tingkat yang lebih tinggi sehingga memiliki prestasi yang meningkat. Seseorang yang menekuni salah satu cabang olahraga diasumsikan memiliki tubuh dengan kondisi fisik yang baik untuk menunjang performanya saat melakukan olahraga tersebut dan memudahkan dalam segala aktivitas yang ditekuninya. Aktivitas olahraga juga digunakan untuk menjaga kebugaran jasmani seseorang.

Berdasarkan survey yang peneliti lakukan terhadap atlet Wushu Kabupaten Limapuluh Kota bahwa belum adanya pemusatan latihan terhadap kondisi fisik atlet dan pelatih tidak memiliki data tentang kemampuan atlet yang mereka bina. Pada saat latihan pelatih hanya terfokus melatih komponen kondisi fisik daya tahan jantung dan paru-paru (cardiorespiratory) saja. Sedangkan untuk mendukung peningkatan prestasi seorang atlet seharusnya seorang pelatih juga mengetahui kualitas komponen-komponen kondisi fisik yang lainnya seperti kekuatan, kelincahan, daya ledak, kecepatan, serta kelentukan. Oleh sebab itu pelatih tidak memiliki data tentang kualitas komponen kondisi fisik sehingga pelatih kurang optimal dalam merumuskan strategi dan program latihan untuk meningkatkan prestasi para atlet.

Hal ini juga dibuktikan dengan uji coba maupun pertandingan yang dilakukan seringkali para atlet kelelahan, padahal waktu pertandingan belum habis. Selanjutnya saat bertanding, para atlet Wushu seringkali kehilangan kecepatan dalam menyerang maupun bertahan dari serangan lawan, tubuh kurang lincah untuk menghindar dan bahkan tendangan kurang bertenaga dan kurang lentur untuk melakukan bantingan kepada lawan. Terbukti, untuk mengikuti PORPROV ke XV tahun 2018 di Padang Pariaman hanya mendapatkan 2 medali emas di cabang Wushu Shansou.

Berdasarkan uraian di atas maka peneliti merasa penting untuk mengangkat permasalahan tersebut dalam bentuk penelitian mengenai tingkat 
kemampuan kondisi fisik atlet wushu di Kabupaten Limapuluh Kota. Oleh karena itu peneliti ingin membuat penelitian dengan judul "Analisis Kondisi Fisik Atlet Wushu Sanda Kabupaten Limapuluh Kota".

Tujuan dari penelitian ini agar mengertahui kondisi fisik yang dimiliki atlet Wushu Sanda Kabupaten Limapuluh Kota. Dan juga dapa memberikan masukan kepada pengurus pencab Wushu Kabupaten Limapuluh Kota agar mengetahui bagaimana tingkat kondisi fisik yang dimiliki oleh atlet Wushu Kabupaten Limapuluh Kota.

\section{METODE PENELITIAN}

Sesuai dengan tujuan penelitian ini yaitu untuk mengetahui kondisi fisik yang dimilikik oleh atlet Wushu Sanda Kabupaten Limapuluh Kota maka digunakan jenis penelitian bersifat deskriptif.Jenis penelitian ini adalah bersifat deskriptif, Arikunto (2006:302) menyatakan bahwa "penelitian deskriptif tidak dimaksudkan untuk menguji hipotesis tertentu, tetapi hanya menggambarkan "apa adanya" tentang sesuatu variabel, gejala atau keadaan". Metode yang digunakan dalam peneltian ini adalah metode survei dengan teknik tes dan pengukuran. Menurut Arikunto (2006: 312), metode survei merupakan penelitian yang biasa dilakukan dengan subjek yang banyak,dimaksudkan untuk mengumpulkan pendapat atau informasi mengenai status gejala pada waktu penelitian berlangsung. Informasi yang diperoleh dari penelitian survei dapat dikumpulkan dari seluruh populasi dan dapat pula dari sebagian populasi.

Penelitian dilaksanakan pada bulan Juni 2019 Penelitian ini dilakukan di lapangan Kubu Gadang, GOR M.Yamin.Teknik pengunpulan data pada penelitian ini menggunakan metode tes. Test adalah sebuah instrumen atau alat yang digunakan untu mendapatkan informasi mengenai individu atau objek .Tes yang dipakai adalah tes dan pengukuran terhadap kondisi fisik.

\section{HASIL PENELITIAN DAN PEMBAHASAN}

\section{Hasil Penelitian}

Hasil penelitian yang dikemukakan dalam bab ini merupakan gambaran tentang kemampuan kondisi fisik pada atlet Wushu Kabupaten Limapuluh Kota. Subyek penelitian adalah atlet Wushu Kabupaten Limapuluh Kota usia 15 - 20 tahun sebanyak 15 orang, namun pada saat penelitian sampel yang dating 
hanya 14 orang karena 1 orang tidak datang tanpa alasan yang jelas.

Data yang dikumpulkan dalam penelitian ini adalah data hasil tes pengukuran yang dideskripsikan dari hasil tes kondisi fisik atlet Wushu Kabupaten Limapuluh Kota. Kondisi Fisik atlet Wushu yang diteliti adalah daya Ledak (power), Kekuatan (strength), Kecepatan (speed), Kelincahan (agility), Daya Tahan (endurance).

Tujuan penelitian ini adalah untuk mengetahui kondisi fisik atlet Wushu Kabupaten Limapuluh Kota. Hasil penelitian kondisi fisik atlet Wushu Kabupaten Limapuluh Kota diukur dengan tes vertical jump, sit up, push up, sprint $60 \mathrm{~m}$, shuttle run $4 \times 5 \mathrm{~m}$, bleep tes. Berdasarkan penelitian yang dilakukan pada masing-masing tes, didapatkan data sebagai berikut.

\section{Tes Vertical Jump}

Berdasarkan table distribusi diatas, maka dapat disimpulkan bahwa dari 14 orang atlet wushu yang dijadikan sampel dalam penelitian ini, diperoleh data kondisi fisik daya ledak atlet wushu Kabupaten Limapuluh Kota sebanyak 1 orang (7.14\%) dalam kategori baik sekali, 2 orang (14.29\%) dalam kategori baik, 8 orang $(57.14 \%)$ dalam kategori sedang dan 3 orang $(21.43 \%)$ dalam kategori kurang. Data di atas menunjukan bahwa komponen kondisi fisik dayaledak atlet wushu Kabupaten Limapuluh Kota sebagian besar dalam kategori sedang.

\section{Tes Sit Up}

Berdasarkan table distribusi diatas, maka dapat disimpulkan bahwa dari 14 orang atlet wushu yang dijadikan sampel dalam penelitian ini, diperoleh data kondisi fisik kekuatan otot perut atlet wushu Kabupaten Limapuluh Kota sebanyak 4 orang (28.57\%) dalam kategori baik sekali, 10 orang $(71.43 \%)$ dalam kategori baik.Data di atas menunjukan bahwa komponen kondisi fisik kekuatan otot perut atlet wushu Kabupaten Limapuluh Kota sebagian besar dalam kategori baik.

3. Tes Push Up

Berdasarkan table distribusi diatas, maka dapat disimpulkan bahwa dari 14 orang atlet wushu yang dijadikan sampel dalam penelitian ini, diperoleh data kondisi fisik kekuatan otot lengan atlet wushu Kabupaten Limapuluh Kota sebanyak 1 orang (7.14\%) dalam kategori baik , 2 orang 
(14.29\%) dalam kategori sedang, dan 12 orang (78.57\%) dalam ketegori kurang. Data di atas menunjukan bahwa komponen kondisi fisik kekuatan otot lengan atlet wushu Kabupaten Limapuluh Kota sebagian besar dalam kategori kurang.

4. Tes Sprint $60 \mathrm{~m}$

Berdasarkan tabel distribusi diatas, maka dapat disimpulkan bahwa dari 14 orang atlet wushu yang dijadikan sampel dalam penelitian ini, diperoleh data kondisi fisik kecepatan atlet wushu Kabupaten Limapuluh Kota sebanyak 1 orang (7.14\%) dalam kategori baik sekali, 5 orang (35.71\%) dalam kategori baik, 7 orang (50\%) dalam kategori sedang dan 1 orang $(7.14 \%)$ dalam kategori kurang. Data di atas menunjukan bahwa komponen kondisi fisik kecepatan atlet wushu Kabupaten Limapuluh Kota sebagian besar dalam kategori sedang.

5. Tes Shuttle Run $4 \times 5 m$

Berdasarkan table distribusi diatas, maka dapat disimpulkan bahwa dari 14 orang atlet wushu yang dijadikan sampel dalam penelitian ini, diperoleh data kondisi fisik kelincahan atlet wushu Kabupaten Limapuluh Kota sebanyak 4 orang (28.57\%) dalam kategori baik sekali, 2 orang (14.29\%) dalam kategori baik, 5 orang (35.71\%) dalam kategori sedang dan 3 orang $(21.43 \%)$ dalam kategori kurang. Data di atas menunjukan bahwa komponen kondisi fisik kelincahan atlet wushu Kabupaten Limapuluh Kota sebagian besar dalam kategori sedang.

6. Tes Multi Stage Fitnes / Bleep Tes

Berdasarkan table distribusi diatas, maka dapat disimpulkan bahwa dari 14 orang atlet wushu yang dijadikan sampel dalam penelitian ini, diperoleh data kondisi fisik kelincahan atlet wushu Kabupaten Limapuluh Kota sebanyak 2 orang (14.29\%) dalam kategori baik, 9 orang (64.29\%) dalam kategori sedang dan 3 orang (21.43\%) dalam kategori kurang.Data di atas menunjukan bahwa komponen kondisi fisik daya tahan atlet wushu Kabupaten Limapuluh Kota sebagian besar dalam kategori sedang.

\section{Pembahasan}

Kondisi Fisik adalah kemampuan fisik atau kesanggupan fisik seseorang dalam bekerja atau berolahraga.Kondisi fisik (physical condition) atau 
kemampuan fisik merupakan salah satu komponen dasar untuk meraih prestasi olahraga di samping komponen teknik, komponen taktik, dan komponen mental (Syafruddin 2012:64).Dari uraian diatas dapat disimpulkan bahwa kondisi fisik merupakan komponen paling mendasar untuk menciptakan suatu prestasi dalam olahraga disamping komponen teknik, taktik dan mental.

Berdasarkan hasil penelitian tentang analisis kondisi fisik atlet Wushu Kabupaten Limapuluh Kota menggunakan tes dan pengukuran kondisi fisik , telah didapatkan hasil dan dapat dideskripsikan sebagai berikut :

1. Pengambilan tes untuk daya ledak otot menggunakan tes vertical jump, dari hasil tes daya ledak otot atlet Wushu sebagian besar masuk dalam kategori sedang yaitu sebanyak 8 orang $57.14 \%$. Diharapkan kepada pelatih dapat memberikan latihan yang dapat meningkatkan daya ledak atlet wushu karena hal tersebut masih bisa ditingkatkan lagi bagi atlet yang masih dalam kategori kurang dan sedang agar bisa memaksimalkan peforma atlet dalam suatu pertandingan. Pelatih juga harus memberikan latihan kecepatan dan kekuatan terlebih dahulu sebelum memasuki latihan power seperti yang telah dijelaskan pada kajian teori. Atlet yang memiliki power yang baik akan mempengaruhi kemantapan seorang atlet dalam melakukan tendangan. Tendangan yang dilakukan dengan power yang baik akan berpengaruh terhadap peforma dan pertahanan lawan. Dalam teknik tendangan mengandung power asiklis. Menurut Hariono (2006:79) bahwa power asiklis adalah suatu gerakan yang kuat dan cepat seperti melompat, melempar, memukul, dan menendang.

2. Pengambilan tes kekuatan otot perut menggunakan tes sit up. Berdasarkan hasil tes yang didapatkan bahwa sebagian besar atlet wushu masuk kedalam kategori baik yaitu sebanyak 10 orang $71.43 \%$ dari total sampel. Kualitas kekuatan otot perut atlet wushu diharapakan dapat di pertahankan agar performa atlet dalam pertandingan agar mencapai hasil yang maksimal. Kekuatan otot perut bagi atlet sangat berfungsi untuk menahan serangan dari lawan seperti tendangan yang mengarah ke perut atlet. Jika atlet tidak memiliki kekuatan otot perut yang baik akan berisiko mendapatkan cedera atau luka dalam saat menerima tendangan dari lawan pada bagian perutnya. Kekuatan perut juga menjadi penting bagi seorang 
atlet wushu untuk melindungi bagian organ-organ didalam perut dari cedera yang membahayakan dengan cara mengkontraksi otot perut. Selain itu otot perut yang baik juga akan mendukung dalam teknik tendangan dan pukulan karena otot perut juga membantu otot tungkai dan otot lengan dalam melakukan tendangan dan pukulan.

3. Pengambilan tes kekuatan otot lengan dilakukan dengan menggunakan tes push up. Berdasarkan hasil tes kekuatan otot lengan atlet wushu sebagian besar masuk dalam kategori kurang yaitu sebanyak 11 orang $78.57 \%$ dari total sampel. Masalah ini sebaiknya menjadi perhatian khusus bagi pelatih untuk lebih meningkatkan latihan kekuatan otot lengan agar dapat meningkat dan minimal masuk dalam kategori sedang supaya dapat mendukung performa atlet untuk menuju puncak prestasi. Kekuatan otot lengan berfungsi pada saat melakukan teknik gerakan pukulan, atlet harus memiliki kekuatan otot lengan yang baik agar pukulan tersebut dapat memberikan efek yang besar bagi lawan tanding. Kekuatan otot lengan juga berfungsi saat melakukan teknik gerakan tangkisan, atlet harus memiliki kekuatan otot lengan yang baik pada saat menangkis serangan lawan. Pada saat melakukan bantingan atlet wushu juga harus memerlukan kekuatan otot lengan agar dapat mengangkat beban tubuh lawan yang merupakan beban luar yang harus diatasi. Pembahasan tersebut didukung oleh Helga dan Manfred dalam Syafruddin (2010:70) mengemukakan kekuatan (strength) merupakan kemampuan untuk menggerakan sebuah masa (tubuh sendiri, lawan, alat) dan juga untuk mengatasi suatu beban melalui kerja otot

4. Pengambilan tes kecepatan dilakukan dengan menggunakan tes sprint 60 $m$, dari hasil tes kecepatan yang dilakukan pada atlet wushu sebagian besar masuk kedalam kategori sedang yaitu sebanyak 7 orang $50 \%$ dari total sampel. Komponen kondisi fisik untuk kecepatam harus lebih ditingkatkan lagi agar mencapai kategori baik. Dalam olahraga wushu kecepatan berperan penting pada saat terjadi figh, kemampuan untuk melalukan serangan secara cepat dan berpindah untuk mengelak dari serangan lawan. Pada olahraga wushu kecepatan yang lebih dominan adalah kecepatan gerak dan kecepatan reaksi, oleh karena itu para atlet 
harus dapat meningkatkan kualitas kecepatan gerak dan reaksinya, maka akan berpengaruh pada performa saat latihan ataupun saat bertanding. Pembahasan tersebut didukung oleh Sukadiyanto (2011:116) Kecepatan adalah kemampuan otot atau sekelompok otot untuk menjawab rangsangan dalam waktu secepat (sesingkat) mungkin. Kecepatan sebagai hasil dari perpaduan dari panjang langkah tungkai dan jumlah langkah. Ada dua macam kecepatan, yaitu kecepatan reaksi dan kecepatan gerak.

5. Pengambilan tes kelincahan menggunakan tes shuttle run. Berdasarkan hasil tes kelincahan atlet wushu sebagian besar masuk dalam kategori sedang sebanyak 5 anak atau $35.71 \%$ dari total sampel. Pelatih diharapkan dapat mempertahankan kualitas kelincahan para atlet dan jika perlu ditingkatkan ke kategori baik agar dapat mendukung performa atlet menuju puncak prestasi di masa depan. Kelincahan menjadi faktor penting bagi atlet wushu dan sangat berfungsi saat dalam pertandingan untuk menghindar dari pukulan ataupun tendangan lawan, maka atlet perlu memindahkan posisi tubuh dengan cepat. Hal tersebut sesuai dengan penjelasan Widiastuti (2014:137) Agility atau kelincahan adalah komponen penting yang dibutuhkan oleh hampir seluruh cabang olahraga. Agility atau kelincahan adalah kemapuan untuk mengubah arah atau posisi tubuh dengan cepat yang dilakukan bersama-sama gerakan lainnya.

6. Pengambilan tes dayatahan dilakukan dengan menggunakan tes multi stage fitness atau bleep tes, dari hasil tes dayatahan yang dilakukan pada atlet wushu sebagian besar masuk kedalam kategori sedang yaitu sebanyak 9 orang $64.29 \%$ dari total sampel. Meskipun pelatih sering menfokuskan latihan kondisi fisik daya tahan tapi tetap saja kemapuan yang dimiliki atlet pada umumnya belum masuk pada kategori baik. Jika seorang atlet mempunyai atau memiliki kapasitas aerobic yang baik maka akan cepat dalam melakukan recovery, sehingga mampu melakukan latihan dengan intesitas tinggi. Hal tersebut didukung oleh penjelasan Sukadiyanto (2011: 61) yang menyatakan bahwa hubungan antara ketahanan dan kinerja (performa) fisik olahragawan diantaranya adalah menambah: (1) kemampuan untuk melakukan aktivitas kerja secara terus menerus dengan intensitas yang tinggi dan dalam jangka waktu lama, (2) 
kemampuan untuk memperpendek waktu pemulihan (recovery) terutama pada cabang olahraga pertandingan dan permainan, (3) kemampuan untuk menerima beban latihan yang lebih berat, lebih lama, dan bervariasi.

\section{KESIMPULAN}

Berdasarkan analisis data dan pembahasan yang telah dipaparkan terdahulu, maka dapat dikemukakan kesimpulan bahwa tingkat Kondisi Fisik Atlet Wushu Kabupaten Limapuluh Kota dalam kategori sebagai berikut : Komponen kondisi fisik daya ledak atlet wushu dikategorikan sedang dengan presentase terbesar sebanyak 57.14\%, Kekuatan Otot Perut atlet wushu dikategorikan baik dengan presentase terbesar sebanyak $71.43 \%$, Kekuatan Otot Lengan atlet wushu dikategorikan kurang dengan presentase terbesar sebanyak $78.57 \%$, Kecepatan atlet wushu dikategorikan sedang dengan presentase terbesar sebanyak 50\%, Kelicahan atlet wushu dikategorikan sedang dengan presentase terbesar sebanyak 35.71\%, Dayatahan atlet wushu dikategorikan sedang dengan presentase terbesar sebanyak $64.29 \%$.

\section{SARAN}

Berdasarkan kesimpulan di atas, ada beberapa saran yang dapat penulis sampaikan yaitu:

1. Bagi atlet yang masih mempunyai kondisi fisik kurang agar lebih meningkatkan dengan cara latihan rutin dan disiplin.

2. Bagi pelatih hendaknya mengembangkan metode tes dan pengukuran kondisi fisik atlet yang berguna untuk mengevaluasi kemampuan fisik atlet sehingga bagi atlet yang masih kurang dapat ditingkatkan.

3. Bagi peneliti selanjutnya diharapkan menggunakan sampel yang lebih bervariasi, tidak hanya atlet laki-laki.

\section{DAFTAR RUJUKAN}

Agus, Apri \& Sepriadi. 2009. Manajemen Kebugaran Jasmani. Padang : Sukabina Press

Ambara, Arya Prasetya. (2017) Hubungan Kondisi Fisik Terhadap Prestasi Atlet Wushu Sanda di Sasana Kim Tiauw Surabaya. Skripsi. Surabaya : Fakultas IImu Keolahragaan Universitas Negeri Surabaya

Arikunto, Suharsimi. (2010). Prosedur penelitian. Jakarta: Rineka Cipta 
Artioli, Guilherme Giannini, dkk (2008) Physiological, Performance, and Nutritional Profile of the Brazilian Olympic Wushu (Kung-fu) Team. National Strength and Conditioning Association. Vol 0 No 0. 1-6

Bafirman dan Agus (2010) Pembentukan Kondisi Fisik. Padang : Wineka Media

Bompa T. O. and Haff G. G. (2009) Theory and Methodology of Training. Canada : Human Kinetics

Darmanto, Arif. (2017) Tingkat Kondisi Fisik Atlet Taekwondo Puslatda PON 2015 Yogyakarta. Skripsi. Yogyakarta : Fakultas IImu Keolahragaan Universitas Negeri Yogyakarta

Gunawan, Gugun Arief. (2007). Beladiri. Yogyakarta : PT Pustaka Insan Madani

Irawadi, Hendri. (2013). Kondisi dan Pengukurannya, Padang : UNP Press

Kurniawan, Feri. (2011). Buku Pintar Olahraga. Jakarta : Niaga Swadaya

Kurniawan, Sarifudin Najib. (2018) Profil Biomotor Atlet Wushu Sanda di Club Sanbo (Wushu Sanda - Muaythai) Kabupaten Magelang. Skripsi. Yogyakarta : Fakultas IImu Keolahragaan Universitas Negeri Yogyakarta

Ni Putu Ruspata Bhyantari dan I Made Muliarta. (2016). Kapasitas Aerobik Mahasiswa Pemain Wushu Lebih Baik Daripada Mahasiswa Bukan Pemain Wuhsu Di Universitas Udayana. Jurnal Medika. Vol 5 No 5:1

Rahmani, Mikanda. 2014 Buku Super Lengkap Olahraga. Jakarta : Dunia Cerdas

Sanchooli, Z., Ghoochan, F. A., Ghoochan, Z. A., \& Aalaee, S. (2014). Determining Physiological Profile of National Iranian Wushu Team. Bulletin of Environment, Pharmacology and Life Sciences, 3(8), 69-72.

Sugiyono. (2015). Metode penelitian pendidikan pendekatan kuantitatif kualitatif, dan R\&D. Bandung: CV. Alfabeta.

Sukadiyanto. (2011). Pengantar Teori Metodologi Melatih Fisik. Yogyakarta : Lubuk Agung Bandung

Syafruddin. (2012). IImu Kepelatihan Olahraga. Padang : FIK UNP.

Undang-Undang RI No.3 (2005) Sistem Keolahragaan Nasional. Bandung : CITRA UMBARA

Vasconcelos, B. B., \& Del Vecchio, F. B. (2017). Wushu Sanda: Color bias, home advantage and motor actions analysis in female matches' from the 13th World Championships. Revista de Artes Marciales Asiáticas, 12(1), 19.

Widiastuti. (2015). Tes dan Pengukuran Olahraga, Jakarta : PT. Raja Grafindo Persada 